\title{
Innovation of Time-saving Model of Aged Service in Community
}

\author{
Zhao Jingwei $^{1},{ }^{\star}$ He Xiaoyang ${ }^{1}$, Chu Chengwei $^{2}$ \\ ${ }^{1}$ School of Politics and Administration, Northwest University of Political Science and Law, Xi'an, \\ Shaanxi, China, 710122 \\ ${ }^{2}$ Anqing Vocational and Technical College, Anqing, Anhui, China, 246000 \\ *Corresponding Author: Zhao Jingwei
}

Keywords: time-saving aged service, communitization, aged human resources

\begin{abstract}
At present, China's problem of population aging is increasingly serious. But the services of traditional family care and social institutions have their own drawbacks. Time-saving aged service in community can fully compensate for the lack of old-age home modeland mobilize the community human resources, forming new aged service supported by the government, society, enterprises and communities. It can smooth the life of the elderly to promote the general improvement of public welfare. This paper analyzes the concept of time-saving model of aged service, demonstrates the feasibility of its development in China and explores the operation model from the perspectives of targeted participants, metering medium, storage and retrieval, services types, funds resources and organization management.
\end{abstract}

\section{Dilemma and Reasons of Aged Service}

The competition in the open society is becoming increasingly fiercer. Rational economic gradually come into the field of familyfrom the market, making family relationships gradually fade. Selfishness and indifference in the traditional family support service is more and more fragile, family endowment functions increasingly shrinking state to provide pension service has become the inevitable choice. And the current pension services still exist cannot meet the rapid growth of pension demand, the supply of old age service is uneven, aging policy fragmentation and other issues.

Aged Service cannot meet the Increasing Demand for Old-age Provision. According to estimates, China in 2050 before and after the elderly population will reach a peak of around 2/5, accounting for of the Asian elderly population, accounting for 1/4 of the world's elderly population. Many scholars have pointed out that China's demand for pension services market is huge. The State Council promulgated and implemented the "social endowment service system construction plan". It is pointed out that China in the "Twelfth Five Year Plan" period, in order to build a home-based, relying on the community; institutions for the support of social endowment service provided the basic framework. At the same time, it also means that only 3\% of the elderly have a pension bed; there are still $97 \%$ of the elderly population needs to rely on home care levels and high cost of living cannot match. They cannot adapt to the working environment.

Inadequate Supply and Uneven Distribution of Aged Service. At present, with the advanced aging trend, the existing pension institutions cannot fully meet the pension needs of the majority of the elderly. There is a big gap, known as the "sunrise industry". On the one hand, the uneven distribution of urban and rural pension services is also serious. The numbers of pension institutions exist in rural towns, only scattered, unable to meet the pension needs of rural areas. Existing pension institutions, mostly small and medium size, generally provide basic material life support 
services, the feature set is single, and the degree of information is low. Theservices of medical care, spiritual comfort and geriatric rehabilitation are few.

Severe Fragmentation of Policies on Ageing. For a long time, affected by many factors, our country in different regions of different groups, there are differences in the implementation of the pension insurance system, showing a "development path patch". First of all, we have established the system of the basic old-age insurance system for urban workers in the cities and towns, and workers in cities and towns as the endowment insurance system for urban residents etc. Secondly, in the rural areas has in view of the different rural community established rural "Five Guarantees", in rural areas, rural double female households, rural endowment insurance, old-age insurance for landless peasants, the new rural pension insurance system.

\section{Concept of Time-saving Model of Aged Service}

In this paper, the "time-saving aged service" model refers to the community as the basis, the members of the community that the pension service providers can be stored to participate in the transaction and services, when they encounter difficulties can be paid from the service. That is the means the elderly provide "their own services" of the new initiatives. In this sense, our time-saving aged service more emphasis on the elderly home care for the elderly, to fully mobilize the elderly human resources.Community "savings" model is one of the forms of mutual assistance. It fully mobilizes the community to provide support services for the use of human resources. Its essence is, in the course of human life to make pension services smooth, which will lead to the general improvement of public welfare. Community "savings" model retains the advantages of home care and mutual support, and make up for their deficiencies. The model can reduce the pressure of the family, and make full use of the human resources of the elderly aged service to achieve the development of low cost, and to meet the demand for elderly ideographic, improve the quality of life of the elderly home care. Time-saving aged service becomes the government, society, enterprise. the strength of the community by the community organizations to provide pension services special time credit institutions". Therefore, it will be an important supplement for the old aged service system in China.

\section{Feasibility Analysis of Time-saving Aged Service in Community}

Compared with other age groups, the elderly have a strong incentive to participate in the "time-savings aged service" model.

Possibility of the Development of Human Resources of the Elderly People. China's aging process is accelerated, the aging population base is growing, aging human resources are huge, with the potential for development.First, the elderly have a lot of leisure time. Passion and time is an essential factor to participate in the "savings" model. Compared with other age groups, the elderly have plenty of leisure time. The second reason is the majority of the elderly health status of the elderly. In the analysis of health, the health status of self-rating is more significant than that of the simple health assessment obtained through medical diagnosis. Third, the macro environment for the development of elderly human resources is gradually improving. Today, the Chinese people's life is stable, rich in material resources, science and technology is developing rapidly, which lays a good foundation for the development of human resources in the old age.

Development of Community Service. National political system reform promotes the scientific community management system, community service has made considerable progress, in order to implement the "savings" model provides a condition. In the government's strong advocacy, in order 
to meet the growing needs of the community residents of the material and cultural needs, to the streets, neighborhood based on the formation of social welfare nature of the community service. From the perspective of the development of community services, there are mainly the following characteristics. First, the gradual standardization of community service carriers. Secondly, the community service areas continue to expand. The third reason is the diversity of community service. In community settings agent service center, it will be planning affairs, party affairs, economic affairs, social security etc. business, centralized processing, simplify procedures and improve the work efficiency, the close relationship between the party and the masses.

Gradual Improvement of Facilities. With the promotion and popularization of computer technology, information network technology, automatic control technology has been used in the community, for community residents to provide a safe, efficient, convenient, and intelligent service to meet the needs of community residents in the growing material and cultural needs. Even the community and the community, the community and the street, take the community service station as the exchange node, the network information platform has been established, and $60 \%$ of the city's urban district has the community management service information network.

Rich Theory of “Time Bank". "The time bank" theory at present mainly focuses on the "money" measurement methods. Bank time creator Edgar Kahn that stored in the time bank service is based on caring responsibility, and personal dedication, belonging to no difference in labor. Therefore, value differencedoes not exist. The difference is only the length of working time to pay. Therefore, any service either in storage or retrieval time of the bank, only need to value the service by hours. That is to say, one hour equals one hour time money.

\section{Model Design of Time-saving Aged Service in Community}

In recent years, some domestic cities and communities have begun to establish "the time bank", mainly relying on in the community. The help objects of the grass-roots government organizations are the seniors and the disabled. The operation principle and mode are similar with them in foreign countries. But, the specific implementation hassome characteristics.

Targeted Participants. Current time-saving aged service mode under the mutual support and mainly to community based on, participants should come from within the community residents, and to able to self-care or semi self mainly the elderly, the age is not restricted, as long as there is the will, may participate in retirement savings. Especially, we canencourage young participants to accumulate support for their old service to provide security services in old age. In addition, some areas have also joined the community correction object, according to the level of crime, allowing such persons to engage in the activities of the appropriate level of security.

Metering Medium According to Kahn Edgar, the founder of "time bank", the value of meaningful work cannot be measured by money. It should be measured by working hours. According to this concept, the pension plan to work as a measurement unit, working hours per hour for 1 hours, that is, 1 hours = 1 time currency. This measure, although do not have the service quality is taken into account, but easy to save the measurement, and the quantity of money in circulation and the actual demand in the quantity of money relative, so there is no inflation possible can preserve and increase the whether depositors when receive required services in original time units as a benchmark. In addition, mutual aid behavior with charitable nature, so time and money also has the characteristics of tax free. It cannot change money freely.

\section{Storage and Retrieval.}

In the United States, as the network popularization rate is high, "time-saving aged service" is the powerful support of Internet communication. Individuals can 24 hours at any time by telephone, the 
landing sites and other forms and time bank to get in touch, quick release various information of the service demand, or check others service requests and query their own storage amount and the detailed records of the transactions. China's time-saving aged service "practice, apply the principle of similar, but due to not fully realize the popularity of the network, therefore mostly take issue" time savings card "to store and reduce service time, which is not conducive to co-ordinate arrangements for volunteer service time, and is not easy to preserve. We should speed up the construction of the hardware. The storage takes extraction method. In addition, we should vigorously publicize the donation concept, in order to protect the elderly and disabled elderly people can enjoy their twilight years.

Services Types. The participants and service objects of the "time-saving aged service" are mainly in the elderly, so the business should also is required for the elderly and to do what he could. The most needs of the elderly are economic support, life care, spiritual comfort and medical care. Elderly people in retirement savings model itself would have to reduce the significance of the old economic burden of providing for the aged, the experience of a mainly to provide an old mutual the pic groups in the United States, business category relates to care, traffic, housework, chat and other basic aspects. On this basis, the business can be added with the development of this model.

Funds Resources. In the "time-saving aged service institutions" exists as a charitable organization. Therefore, not to the membership fees, it is the source of funds to individuals, businesses, foundations, government agencies, donations and cooperation based, in addition to the sale of members of the financing of handmade products. The scholar of Dang Junwu in our country believes that the time-saving aged service is only the national model, because "time-saving aged service" must have the integration of national credit, national information technology, national standards and national management network computingto form scale. "Time-saving aged service" should be with the development of social economy and gradual independence, if long-term rely on state support, misappropriation of social resources, cause against other taxpayers.

\section{Organization Management}

China's time-saving aged service was carried out late. The mechanism is not mature and there is no unified organization. According to China's national conditions and practice experience, it needs to rely on the "savings endowment" mode in the early establishment at present. We'd better to find the venerable leaders in the communityserves as a staff member.Because community leaders and respected people with charisma that can later be by old people enthusiastic staff or hire a professional social workers as workers. Staff responsible for organization of elderly volunteers training learning, apply for membership registration and answer the phone calls and records of management "savings", open discussion will understand the elderly demand, coordinate volunteers between interest and visit recipients. Due to the retirement savings pattern also belongs to new things.So in the actual operation it still exist some problems, such as the lack of institutional guarantee and low internet penetration rate. These problems remain to be solved in the future.

\section{Acknowledgements}

1. Program of National Social Science Foundation: Research on Modern Rules and Regulations in the Innovation of Rural Social Management System (Grant No. 15SA0212)

2. Program of National Social Science Foundation: Research on Rural Society Risk and Public Safety Governance (Grant No. 13XGL014)

3. Periodical Results of the Research on Innovation of democratic consultation and Social 
Management in Grass-roots Society of Shaanxi

\section{References}

[1] MaGuixia, The Applications of "Time Bank" Mode in Aging Care at Home, J., Journal of Nanjing University of Science and Technology, 2010, 23(6): 116-120.

[2] Chen Gong, DuPeng, Chen Yi, A Think on the Time-saving Problems of Supporting the Old, Population \&Economics, 2001(6): 67-73. 